\title{
Thermalized Epoxide Formation in the Atmosphere
}

\author{
Moller, Kristian $\mathrm{H}$.
}

2019-12-12

Moller , K H , Kurten , T , Bates , K H , Thornton , J A \& Kjaergaard , H G 2019 , '

Thermalized Epoxide Formation in the Atmosphere ' , Journal of Physical Chemistry A, vol. 123 , no. 49 , pp. 10620-10630 . https://doi.org/10.1021/acs.jpca.9b09364

http://hdl.handle.net/10138/322132

https://doi.org/10.1021/acs.jpca.9b09364

acceptedVersion

Downloaded from Helda, University of Helsinki institutional repository.

This is an electronic reprint of the original article.

This reprint may differ from the original in pagination and typographic detail.

Please cite the original version. 
This document is confidential and is proprietary to the American Chemical Society and its authors. Do not copy or disclose without written permission. If you have received this item in error, notify the sender and delete all copies.

\section{Thermalized Epoxide Formation in the Atmosphere}

\begin{tabular}{|c|c|}
\hline Journal: & The Journal of Physical Chemistry \\
\hline Manuscript ID & Draft \\
\hline Manuscript Type: & Article \\
\hline $\begin{array}{r}\text { Date Submitted by the } \\
\text { Author: }\end{array}$ & $\mathrm{n} / \mathrm{a}$ \\
\hline Complete List of Authors: & $\begin{array}{l}\text { Møller, Kristian; University of Copenhagen, Department of Chemistry } \\
\text { Kurtén, Theo; Helsingin Yliopisto, Department of Physical Sciences } \\
\text { Bates, Kelvin; Harvard University Center for the Environment, } \\
\text { Thornton, Joel; University of Washington, Atmospheric Sciences } \\
\text { Kjaergaard, Henrik Grum ; Copenhagen University, Chemistry }\end{array}$ \\
\hline
\end{tabular}

\section{SCHOLARONE \\ Manuscripts}




\title{
Thermalized Epoxide Formation in the
}

\section{Atmosphere}

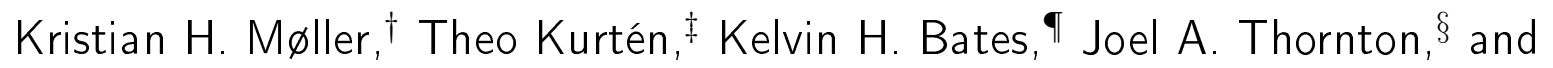 \\ Henrik G. Kjaergaard*,† \\ $\dagger$ Department of Chemistry, University of Copenhagen, Universitetsparken 5, DK-2100 \\ Copenhagen Ø, Denmark \\ $\ddagger$ University of Helsinki, Department of Chemistry, POB 55, FIN-00014 Helsinki, Finland \\ IHarvard University, Center for the Environment, 29 Oxford St., Cambridge, MA, USA \\ 02138 \\ $\S$ Department of Atmospheric Sciences, University of Washington, Seattle, Washington \\ 98195, United States \\ E-mail: hgk@chem.ku.dk \\ Phone: +45-35320334. Fax: +45-35320322
}

\begin{abstract}
Epoxide formation was established a decade ago as a possible reaction pathway for $\beta$-hydroperoxy alkyl radicals in the atmosphere. This epoxide-forming pathway required excess energy in order to compete with $\mathrm{O}_{2}$-addition, as the thermal reaction rate coefficient is many orders of magnitude too slow. However, recently, a thermal epoxideforming reaction was discovered in the isoprene $+\mathrm{OH}$ oxidation pathway. Here, we computationally investigate the effect of substituents on the epoxide formation rate coefficient of a series of substituted $\beta$-hydroperoxy alkyl radicals. We find that the thermal reaction is likely to be competitive with $\mathrm{O}_{2}$-addition when the alkyl radical


carbon has an OH-group, which is able to form a hydrogen bond to a substituent on the other carbon atom in the epoxide ring being formed. Reactants fulfilling these requirements can be formed in the $\mathrm{OH}$-initiated oxidation of many biogenic hydrocarbons. Further, we find that $\beta$-OOR alkyl radicals react similarly to $\beta$-OOH alkyl radicals, making epoxide formation a possible decomposition pathway in the oxidation of ROOR peroxides. GEOS-Chem modeling shows that the total annual production of isoprene dihydroxy-hydroperoxy-epoxide is $23 \mathrm{Tg}$, making it by far the most abundant C5-tetrafunctional species from isoprene oxidation.

\section{Introduction}

In the atmospheric oxidation of volatile organic compounds (VOCs), a plethora of species with different functional groups are formed. ${ }^{1}$ These typically include aldehydes, alcohols and hydroperoxides. ${ }^{1}$ In 2009, an epoxide (isoprene epoxyiol, IEPOX) was observed as a major product from the $\mathrm{OH}$-initiated oxidation of isoprene (2-methylbuta-1,3-diene, $\mathrm{C}_{5} \mathrm{H}_{8}$ ), the most highly emitted biogenic VOC. ${ }^{2-6}$ Addition of $\mathrm{OH}$ and $\mathrm{O}_{2}$ to isoprene forms a hydroxy peroxy radical which reacts with $\mathrm{HO}_{2}$ to form isoprene hydroxy hydroperoxide (ISOPOOH), see Scheme 1. The accepted mechanism for formation of IEPOX involves the addition of a hydroxyl radical to ISOPOOH to form a $\beta$-hydroperoxy alkyl radical, where the radical is on the carbon atom adjacent to the carbon atom with the hydroperoxy group. ${ }^{2,7}$ The epoxide, IEPOX, is then formed by a concerted loss of $\mathrm{OH}$ from the hydroperoxy group and formation of an new $\mathrm{CO}$ bond (see Scheme 1). The calculated thermalized unimolecular rate coefficient for formation of IEPOX from the $\beta$-hydroperoxy alkyl radical is fast at around $10^{3}-10^{4} \mathrm{~s}^{-1} \cdot{ }^{8}$ However, the competing reaction is addition of molecular oxygen to form a $\beta$-hydroperoxy peroxy radical with a much faster pseudo first-order reaction rate coefficient on the order of $10^{7} \mathrm{~s}^{-1}-10^{8} \mathrm{~s}^{-1} \cdot{ }^{9-11}$ The epoxide formation is competitive only because the $\mathrm{OH}$-addition provides the alkyl radical with about $30 \mathrm{kcal} / \mathrm{mol}$ of excess energy, which is sufficient to rapidly cross the $10-13 \mathrm{kcal} / \mathrm{mol}$ barrier for epoxide formation. ${ }^{8}$ Experimental 
results suggest that the IEPOX yield from ISOPOOH $+\mathrm{OH}$ is greater than $70 \%$, while addition of $\mathrm{O}_{2}$ accounts for less than $15 \%$ and the remaining $~ 10-15 \%$ of ISOPOOH reacts by $\mathrm{H}$ abstraction, primarily of the hydroperoxy hydrogen. ${ }^{2,8}$

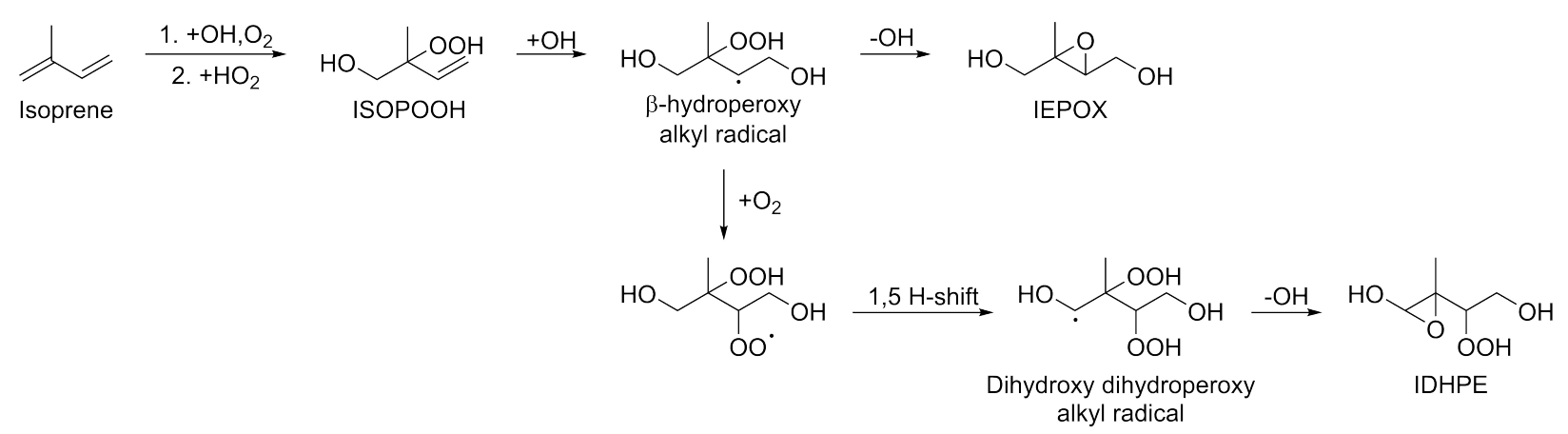

Scheme 1: Reaction mechanism leading from isoprene to one isomer of IEPOX and the isoprene dihydroxy hydroperoxy epoxide (IDHPE) found by D'Ambro et al. ${ }^{12}$.

An analogous mechanism has been observed in the $\mathrm{OH}$-initiated oxidation of isoprene-derived hydroxy nitrates with loss of $\mathrm{NO}_{2}$ rather than $\mathrm{OH} .{ }^{13}$ For this, experiments with varying pressure have confirmed that the formation of IEPOX is indeed driven by the excess energy, as decreased pressure increases the epoxide yield significantly. However, with an IEPOX yield of about $15 \%$ at $1 \mathrm{~atm}$, this pathway for IEPOX formation is less efficient than that from ISOPOOH.

The requirement for excess energy in the formation of IEPOX suggests that atmospheric epoxide formation via this mechanism is limited to unsaturated systems which may react by radical addition. The $\beta$-hydroperoxy alkyl radicals formed in the atmosphere by peroxy radical H-shifts do not typically possess excess energy, as these reactions are usually close to thermoneutral, and thus seem excluded from epoxide formation. ${ }^{14,15}$ However, in a recent study, epoxide formation was found to be competitive with $\mathrm{O}_{2}$-addition without the need for excess energy in a multifunctional isoprene oxidation intermediate. ${ }^{12}$ Specifically, the system studied was a dihydroxy dihydroperoxy alkyl radical $\left(\mathrm{C}_{5} \mathrm{H}_{11} \mathrm{O}_{6}\right)$ obtained following a 1,5 H-shift in the non-IEPOX ISOPOOH oxidation pathway (see Scheme 1). ${ }^{12}$ The calculated 
canonical reaction rate coefficients for epoxide formation in the two different isomers of this system are $9 \times 10^{9} \mathrm{~s}^{-1}$ and $3 \times 10^{8} \mathrm{~s}^{-1}$, respectively, and thus comparable to or faster than the competing $\mathrm{O}_{2}$-addition. The mass corresponding to the epoxide product formed (IDHPE) was measured experimentally by high-resolution time-of-flight chemical ionization mass spectrometry (HRToF-CIMS). ${ }^{12,16}$ Thermalized epoxide formation following H-abstraction from ISOPOOH has also been hypothesized as one possible mechanism to a compound with a mass observed experimentally. ${ }^{8}$

In a recent review on the gas-phase chemistry of isoprene, the yield of epoxides is mentioned as an important remaining challenge with significant chemical implications. ${ }^{7}$ The possibility of epoxide formation without the need for excess energy suggests that epoxide formation may be more ubiquitous in atmospheric oxidation than currently thought. ${ }^{12}$ Interestingly, epoxides formed by mechanisms analogous to the ones shown in Scheme 1 will generally have molecular formulas corresponding to carbonyl compounds and could have been observed experimentally already, but misassigned.

Epoxides have been linked to the formation of secondary organic aerosol (SOA), which has important implications for the climate and human health. ${ }^{17-20}$ The products of IEPOX have been observed as key constituents of ambient SOA, and IEPOX has been shown experimentally to lead to growth of SOA. ${ }^{21-24}$ In laboratory studies, 2,3-epoxy-1,4-butanediol (BEPOX, the butadiene derivative of IEPOX) and the lactone hydroxymethyl-methyl- $\alpha^{-}$ lactone (HMML) have also been observed to contribute significantly to SOA growth. ${ }^{2,25,26}$ Epoxides are thus key components for atmospheric SOA formation. ${ }^{24,25,27}$ The SOA-forming ability of epoxides has been attributed to reactive uptake onto existing aerosols followed by acid-catalyzed ring-opening and reaction with nucleophiles in the aerosol (most importantly water and sulphate). ${ }^{2,25,28}$ This has been shown to result in dimerization and formation of carboxylic acids, polyols and organosulphates. ${ }^{25,27}$ Furthermore, reactions between epoxides 
and amines in water have been reported, providing an additional potential route for SOA formation from epoxides. ${ }^{23,29,30}$ The efficient SOA formation from epoxides means that additional sources of atmospheric epoxides would provide additional atmospheric SOA.

To assess the importance of atmospheric epoxide formation, we present a systematic highlevel theoretical study of the rate coefficients for epoxide formation for a total of more than 70 different $\beta$-hydroperoxy alkyl radicals with different atmospherically relevant substituents (see Figure S1). We focus on systems with oxygen-containing substituents as those are typically encountered during atmospheric oxidation and autoxidation processes and thus expand upon the previous experimental and theoretical studies. ${ }^{31-41}$

Based on our calculated reaction rate coefficients, we present some simple guidelines for when epoxide formation without excess energy needs to be considered as a potentially competitive reaction. We also investigate the formation of epoxides from $\beta$-nitrooxy alkyl radicals, $\beta$ peroxy alkyl radicals as well as the formation of larger cyclic ethers, all of which have been observed under various conditions. ${ }^{13,31,42,43}$ Finally, to assess the atmospheric implication of the epoxide formation pathways, we include these into a global atmospheric chemical model of isoprene oxidation (GEOS-Chem) to determine the scope and importance of thermalized epoxide formation. ${ }^{7,44,45}$

\section{Theory and Methods}

\section{Calculation of Reaction Rate Coefficients}

Reaction rate coefficients are calculated using the approach outlined by Møller et al. ${ }^{14}$ with slight modifications to account for the different reaction type. An initial structure of the reactant and transition state of each reaction is optimized at the B3LYP $/ 6-31+\mathrm{G}(\mathrm{d})$ level in Gaussian 09. ${ }^{46-51}$ These structures are used as starting points for systematic conformer 
searches in Spartan'14 with the "KEEPALL" keyword to avoid loss of conformers. ${ }^{52}$ The conformer searches are done using MMFF. ${ }^{53}$ Any incorrectly placed charge on the radical center, $x$, is removed using the keyword "FFHINT $=x \sim \sim+0 " .{ }^{14}$ For the transition states, constrained conformer searches are employed by constraining the bond lengths of the O-O bond being broken, the $\mathrm{C}-\mathrm{O}$ bond being formed and the original $\mathrm{C}-\mathrm{OOH}$ bond in the transition state (TS) moeity. The bond lengths are constrained to the optimized values for an arbitrary conformer of the system. For the TSs, the bonding pattern of the reactant is used for the MMFF calculation.

All structures resulting from the conformational sampling are optimized in Gaussian 09 at the B3LYP $/ 6-31+\mathrm{G}(\mathrm{d})$ level. For the transition states, constrained optimizations using the same constraints as for the conformational sampling were done. Following the constrained optimizations, unique structures were identified by comparing their electronic energies and dipole moments using the script "Confcheck" and duplicate structures were removed. ${ }^{14,54}$ Finally, non-constrained transition state optimizations were done for all unique transition state structures.

For the optimized reactants $(\mathrm{R})$ and transition states, duplicate structures were eliminated as described above. Only conformers within $2 \mathrm{kcal} / \mathrm{mol}$ in electronic energy of the lowestenergy structure were optimized at the $\omega$ B97X-D/aug-cc-pVTZ level, which has been shown to introduce significant computational savings at little loss of accuracy. ${ }^{14,55-57}$ For some of the smaller systems we include all conformers. Subsequent frequency calculations were conducted to confirm the nature of the stationary points located and obtain thermodynamic properties. A few structures with the $-\mathrm{ONO}_{2}$ substituent yielded small imaginary frequencies. These were removed by including the additional keywords Integral(Acc2e=12) and $\mathrm{CPHF}$ (grid=ultrafine). For the lowest-energy conformer of reactant and transition state, ROHF-ROCCSD(T)-F12a/VDZ-F12 (abbreviated F12) single-point calculations were done 
in Molpro 2012 for the $\omega$ B97X-D/aug-cc-pVTZ geometries. ${ }^{58-63}$

Reaction rate coefficients were calculated using multi-conformer transition state theory (MCTST): ${ }^{14,64-66}$

$$
k=\kappa \frac{k_{B} T}{h} \frac{\sum_{i}^{T S \text { conf. }} \exp \left(\frac{-\Delta E_{i}}{k_{B} T}\right) Q_{T S_{i}}}{\sum_{j}^{\text {conf. }} \exp \left(\frac{-\Delta E_{j}}{k_{B} T}\right) Q_{R_{j}}} \exp \left(-\frac{E_{T S}-E_{R}}{k_{B} T}\right)
$$

where $\kappa$ is the tunneling coefficient, $k_{B}$ it the Boltzmann constant, $T$ is the absolute temperature in Kelvin and $h$ is Planck's constant. The two summations formally run over all transition state and reactant conformers, respectively, but here only those up to $2 \mathrm{kcal} / \mathrm{mol}$ are included. $\Delta E_{i}$ is the $\omega \mathrm{B} 97 \mathrm{X}-\mathrm{D} /$ aug-cc-pVTZ zero-point corrected energy of transition state conformer $i$ relative to the lowest-energy transition state conformer and $\Delta E_{j}$ is the corresponding relative energy of reactant conformer $j . Q_{T S_{i}}$ and $Q_{R_{j}}$ are the partition functions of transition state conformer $i$ and reactant conformer $j$, evaluated at the lowest vibrational energy level. $E_{T S}$ and $E_{R}$ in the last term are $\omega$ B97X-D/aug-cc-pVTZ zero-point corrected F12 energies of the lowest-energy conformer of transition state and reactant, respectively. ${ }^{14}$ Due to the relatively large mass being transferred in these reactions, tunneling is of little importance. Eckart tunneling coefficients for a set of four representative epoxide formation reactions range from 1.67 to 2.36 (see Section $\mathrm{S} 2$ for details). ${ }^{67} \mathrm{~A}$ tunneling correction factor of two has therefore been applied to all absolute rate coefficients presented here. All rate coefficients are calculated at $298.15 \mathrm{~K}$.

The MC-TST reaction rate coefficients presented here are high-pressure limit values. We ran a Master Equation, Rice-Ramsperger-Kassel-Marcus (RRKM) simulation using MultiWell for two representative systems with fast epoxide formation rate coefficients (see Section S3). ${ }^{68-70}$ For the fastest reaction studied here (System $\mathbf{M}$ in Table $2, k_{M C-T S T}=1.0 \times 10^{10}$ $\mathrm{s}^{-1}$ ), the rate coefficient after $300 \mathrm{ps}$ at 1 atm is about a factor of 15 lower than the high- 
pressure limit and for the slower reaction of system $\mathbf{E}\left(k_{M C-T S T}=1.7 \times 10^{8} \mathrm{~s}^{-1}\right)$, the rate coefficient at 1 atm is only about a factor of 5 below the high-pressure limit. In both cases, the reaction remains competitive with the pseudo first-order rate coefficient for $\mathrm{O}_{2}$-addition and we thus expect the MC-TST rate coefficients to remain qualitatively correct for the reaction studied. For $\mathrm{O}_{2}$-addition to the alkyl radicals, we adopt the experimental value of $2.9 \times 10^{-12} \mathrm{~cm}^{3}$ molecule $\mathrm{s}^{-1}$ for the 2-methyl-1-propyl radical at $298 \mathrm{~K}$ as a representative system. ${ }^{9}$ Assuming 1 atm of pressure and $20 \% \mathrm{O}_{2}$, this corresponds to a pseudo first-order rate coefficient of $\mathrm{O}_{2}$-addition of $1.5 \times 10^{7} \mathrm{~s}^{-1}$. Naturally, the rate of $\mathrm{O}_{2}$-addition depends on the system, but based on reviewed values, for most systems it is expected to fall in the range $5 \times 10^{6} \mathrm{~s}^{-1}-2 \times 10^{8} \mathrm{~s}^{-1} \cdot{ }^{10}$

To ensure that the lowest-energy Hartree-Fock (HF) solution was used as reference function for the F12 calculations, we used the approach by Vaucher and Reiher ${ }^{71}$ which mixes random pairs of occupied and unoccupied orbitals (see Section S4). This is found to be important for the transition states of these epoxide formation reactions, as lower-energy HF solutions are obtained in about $15 \%$ of the transition states in these reactions with this orbital mixing approach.

To check for potential multi-reference character, MRCISD(3,3)-F12 calculations were done for selected test systems (Section S5). These yield barrier heights comparable to the ones obtained using CCSD(T)-F12/VDZ-F12//wB97X-D/aug-cc-pVTZ for the unsubstituted system. In agreement with the $\operatorname{CCSD}(\mathrm{T})-\mathrm{F} 12$ calculations, MRCISD predicts a significant decrease in barrier heights for epoxide formation with increasing functionalization of the $\alpha$ hydroperoxy alkyl radical. However, this decrease is somewhat less steep than that predicted by $\operatorname{CCSD}(\mathrm{T})-\mathrm{F} 12$, possibly due to a less complete treatment of dynamic correlation involved in hydrogen bonding at the MRCISD level because of the lack of triple excitations. 


\section{GEOS-Chem Modeling}

We used GEOS-Chem UCX v11-02c to conduct three-dimensional global simulations of the epoxidation chemistry described here within the isoprene oxidation system. GEOS-Chem integrates assimilated meteorological observations from the NASA Goddard Earth Observing System - Fast Processing (GEOS- FP) of the NASA Global Modeling and Assimilation Office (GMAO). We employed the standard HEMCO emissions configuration, ${ }^{76}$ which incorporates isoprene emissions from MEGAN v2.1. ${ }^{6}$ Simulations were performed on a global grid of $4^{\circ}$ latitude by $5^{\circ}$ longitude with 72 vertical levels through the stratosphere, and were conducted for one year following a preliminary initialization year. Results are reported as troposphere-wide averages over the period from 1 July 2014 to 1 July 2015.

The isoprene oxidation chemistry was simulated using the Mini-CIM model presented in Bates and Jacob ${ }^{45}$, based on the "reduced-plus" mechanism described in the recent review by Wennberg et al. ${ }^{7}$ The model was updated to include the diastereomerically averaged calculated H-shift rate coefficients from Møller et al. ${ }^{15}$ 


\section{Results and Discussion}

The formation of epoxides from $\beta$-hydroperoxy alkyl radicals occurs as a concerted reaction in which the O-O bond of the hydroperoxy group is broken with loss of $\mathrm{OH}$ and simultaneous formation of a new C-O bond. The simplest system is the 2-hydroperoxy ethyl radical (Figure 1) which has two hydrogen substituents on the hydroperoxide carbon (C1) and two hydrogen substituents on the alkyl carbon (C2). The rate coefficient of epoxide formation for this system is calculated with our MC-TST approach to be $2.6 \mathrm{~s}^{-1}$. Previous studies have found calculated rate coefficients for this reaction at various levels of theory that span the range from $1 \mathrm{~s}^{-1}$ to $5 \times 10^{2} \mathrm{~s}^{-1}$ at $298.15 \mathrm{~K}^{34-41}$

The energetics shown in Figure 1 are similar for all the epoxide formation reactions studied. The reaction is exothermic leading to a product complex with only a low barrier to release of $\mathrm{OH}$. With a reaction rate coefficient of $2.6 \mathrm{~s}^{-1}$, even the unsubstituted system has a fast unimolecular reaction. However, as the competing $\mathrm{O}_{2}$-addition occurs at a rate around $10^{7}$ $\mathrm{s}^{-1}$, the reaction rate coefficient needs to be much higher to be competitive. As we will show, replacing the hydrogens on the carbons with different substituents can lead to large decreases in the barrier height and thus large increases in the rate coefficients of epoxide formation. 


\section{Single Substituent}

As shown in Table 1, a single substituent on either the hydroperoxy carbon $(\mathrm{C} 1)$ or the alkyl radical carbon $(\mathrm{C} 2)$ can have a drastic effect on the calculated reaction rate coefficient. A single substituent on the $\mathrm{C} 1$ carbon can increase the rate coefficient by approximately a factor of 1000 and at the $\mathrm{C} 2$ carbon by up to about a factor of 300 . If the reactant has a delocalized radical, we find significant reductions of the reaction rate coefficient for epoxide formation, as observed before. ${ }^{41}$ The effect of increasing the length of an alkyl substituent from methyl to ethyl is relatively limited (less than a factor of ten). This suggest that the length of the carbon chain is not significant for the rate coefficient. It is, however, quite clear 
from the table, that no single substituent is able to explain the very fast rate coefficient of epoxide formation observed by D'Ambro et al. ${ }^{12}$

Table 1: Calculated reaction rate coefficients $\left(\mathrm{s}^{-1}\right)$ for epoxide formation with a single substituents at either the hydroperoxide carbon $(\mathrm{C} 1)$ or the alkyl radical carbon $(\mathrm{C} 2)$. The three remaining substituents are all H's. ${ }^{a}$

\begin{tabular}{lcc}
\hline & $\mathrm{C}^{\mathrm{b}}$ & $\mathrm{C} 2^{\mathrm{b}}$ \\
\hline$-\mathrm{H}$ & $2.6 \times 10^{0}$ & $2.6 \times 10^{0}$ \\
$-\mathrm{CH}_{3}$ & $3.0 \times 10^{2}$ & $1.9 \times 10^{1}$ \\
$-\mathrm{C}_{2} \mathrm{H}_{5}$ & $3.6 \times 10^{1}$ & $5.2 \times 10^{1}$ \\
$=\mathrm{CH}_{2}$ & $2.0 \times 10^{-8}$ & $1.7 \times 10^{-2}$ \\
$-\mathrm{C}=\mathrm{CH}_{2}$ & $1.9 \times 10^{1}$ & $1.8 \times 10^{-3}$ \\
$-\mathrm{C}=\mathrm{O}$ & $4.1 \times 10^{0}$ & $2.3 \times 10^{-3}$ \\
$-\mathrm{CH}_{2} \mathrm{OOH}$ & $3.2 \times 10^{2}$ & $9.7 \times 10^{0}$ \\
$-\mathrm{CH}_{2} \mathrm{OH}$ & $2.7 \times 10^{3}$ & $1.9 \times 10^{1}$ \\
$-\mathrm{OH}$ & $3.3 \times 10^{1}$ & $7.2 \times 10^{1}$ \\
$-\mathrm{OOH}$ & $1.3 \times 10^{3}$ & $-{ }^{\mathrm{c}}$ \\
$-\mathrm{OCH}$ & $3.1 \times 10^{2}$ & $7.8 \times 10^{2}$ \\
$=\mathrm{O}_{3}$ & $5.7 \times 10^{-6}$ & $1.3 \times 10^{-5}$ \\
$-\mathrm{ONO}_{2}$ & $3.3 \times 10^{0}$ & $-{ }^{\mathrm{c}}$ \\
\hline
\end{tabular}

${ }^{\text {a }}$ MC-TST including all conformers, i.e. without the $2 \mathrm{kcal} / \mathrm{mol}$ cut-off employed. All rate coefficients include a tunneling factor of 2 .

b See Figure 1.

c Reactant spontaneously decomposes to yield carbonyl with loss of either $\mathrm{OH}$ or $\mathrm{NO}_{2}$, and will not form epoxides. ${ }^{77,78}$

\section{Multiple Substituents}

Previously, it has been observed, both experimentally and theoretically, that increased degree of substitution around the epoxide forming center tends to increase the rate of epoxide formation. ${ }^{31,36,37,41}$ To assess if the single-substituent effects shown in Table 1 are additive (multiplicative), we calculated the rate coefficients for the systems with zero to four methyl 
or hydroxy substituents. These were chosen as representative substituents with atmospheric prevalence and relevance. Individually, each of these as a single substituent increase the rate coefficient roughly by a factor of between 10 and 100 (see Table 1).

The calculated rate coefficients for systems with an increasing number of methyl and hydroxy substituents are shown in Figure 2. It is clear that increased substitution increases the rate coefficient. For the methyl substituents, the increase is largely independent of the position at $\mathrm{C} 1$ or $\mathrm{C} 2$. Each additional methyl substituent increases the rate coefficient by roughly a factor of 50. However even with four methyl substituents, the rate coefficient of about $10^{5} \mathrm{~s}^{-1}$ is still about two orders of magnitude from being competitive with $\mathrm{O}_{2}$-addition. For the $\mathrm{OH}$ substituent, the pattern is very different. For the three systems with an OH-group on both of the two carbon atoms, rates competitive with the $\mathrm{O}_{2}$-addition are observed. This motif thus leads to a very large increase in the rate coefficient, which cannot be explained by simple additive effects. Characteristic for the three systems with really fast epoxide formation is the presence of a hydrogen bond (H-bond) from a $\mathrm{C} 2 \mathrm{OH}$-group to another OH-group in the lowest-energy conformer of the transition state (Figure 3). The hydrogen bond in the transition state is stronger than the corresponding hydrogen bond in the reactant (Section S6). This lowers the energy of the transition state more than the reactant thus decreasing the reaction barrier and thereby increasing the rate of reaction. 


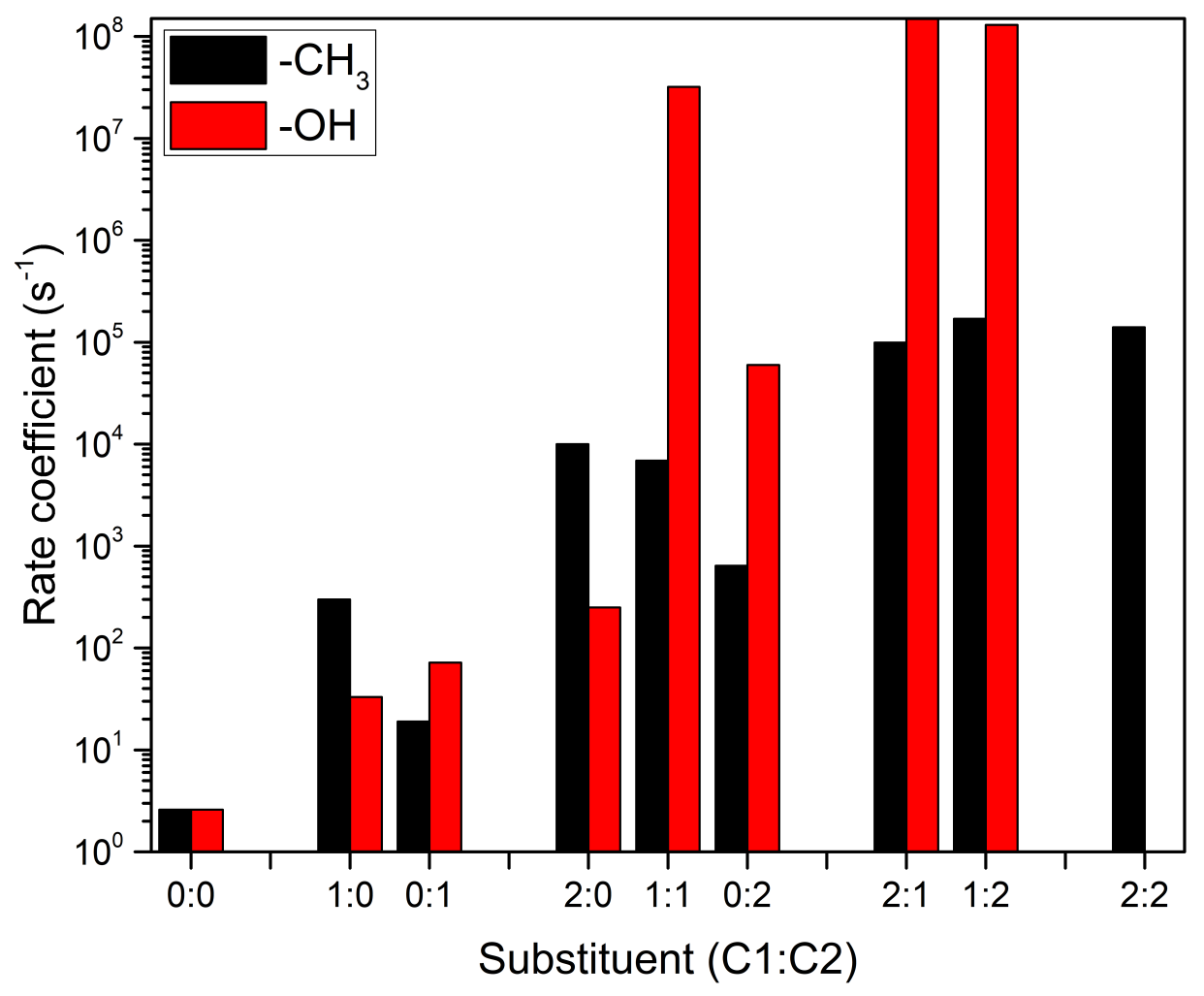

Figure 2: Reaction rate coefficient for epoxide formation in the systems with zero to four methyl or $\mathrm{OH}$ substituents. For the system with four $\mathrm{OH}$ substituents, the transition state geometry optimization would not converge.

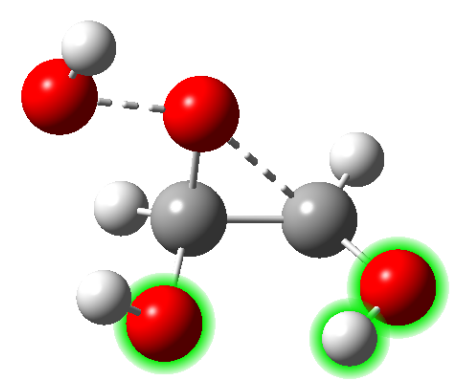

Figure 3: Lowest-energy transition state conformer of the system with an OH-group on each carbon atom. The green auras highlight the H-bond.

\section{Fast Epoxide Formation Reactions}

The epoxide formation reactions reported by D'Ambro et al. ${ }^{12}$ have calculated reaction rate coefficients on the order of $10^{9} \mathrm{~s}^{-1}$ and characteristic for the isomer with the fastest rate of epoxide formation in that system is that it has a hydroxy group on the alkyl radical carbon 

carbon $(\mathrm{C} 1)$. Based on this motif, we devised the model system shown in the insert in Figure 4, which has a hydroxy group at $\mathrm{C} 2$ and a methyl and a variable substituent (R) at C1. By varying the substituent $R$, we can progress from a relatively simple system to the complex system studied in D'Ambro et al. ${ }^{12}$ The reaction rate coefficients for the simplest system for which $\mathrm{R}$ is a hydrogen atom is $5.8 \times 10^{2} \mathrm{~s}^{-1}$. Substituting the hydrogen at $\mathrm{C} 1$ by a methyl group $\left(\mathrm{R}=\mathrm{CH}_{3}\right.$ in Figure 4) increases the rate of reaction by about a factor of 1000 , which is almost a factor of 10 more than expected from the results shown in Table 1 and Figure 2. This again suggests that the rate coefficient of epoxide formation cannot be described by simple addition of substituent effects. Even more significant is the increase in the rate coefficient when changing the $\mathrm{C} 1$ R-group to a hydroperoxy methyl group $\left(\mathrm{R}=\mathrm{CH}_{2} \mathrm{OOH}\right.$, Figure 4, third point). Based on the results in Table 1, we would expect these two groups to behave similarly and both increase the rate coefficient by about a factor of 10 to 100 relative to hydrogen. However, for this model system, the rate coefficient of epoxide formation increases by more than three orders of magnitude between the methyl and hydroperoxy methyl substituents, the latter becoming highly competitive with $\mathrm{O}_{2}$-addition. This clearly suggests some synergistic effect of the multiple substituents present in this system and shows that even oxygen atoms not attached to the two central carbon atoms can have a drastic effect on the rate coefficient. Further increasing the size of the $\mathrm{R}$ substituent towards the system in D'Ambro et al. ${ }^{12}$ has minor effects on the calculated rate coefficients with all being faster than $\mathrm{O}_{2}$-addition.

As observed for the systems with multiple $\mathrm{OH}$ substituents described in the previous section, the common factor for the systems with rate coefficients above $10^{7} \mathrm{~s}^{-1}$ is a hydrogen bond in the transition state from the $\mathrm{OH}$ group at $\mathrm{C} 2$ to another oxygen in the compound (Figure 3), apart from system $\mathbf{G}$ in Table 2 which has an $-\mathrm{OCH}_{3}$-group at $\mathrm{C} 2$. This hydrogen bond is stronger in the transition state than in the reactant (Section S6) thus lowering the reaction 
barrier and thereby increasing the rate coefficient of epoxide formation. This hypothesis is supported by the fact that replacing the $-\mathrm{OH}$ group at $\mathrm{C} 2$ in the system with $\mathrm{R}=\mathrm{CH}_{2} \mathrm{OOH}$ in Figure 4 with a $-\mathrm{CH}_{3}$ (eliminating the option for H-bonding) reduces the rate coefficient by almost four orders of magnitude to $3.6 \times 10^{5} \mathrm{~s}^{-1}$. From Table 1, comparable rate coefficients would be expected for the $-\mathrm{CH}_{3}$ and $-\mathrm{OH}$ substituents. All systems with rate coefficients greater than $10^{7} \mathrm{~s}^{-1}$ studied here are summarized in Table 2. The epoxide formation rate coefficients for all studied systems (including those slower than $10^{7} \mathrm{~s}^{-1}$ ) are given in Table S1.

The hydrogen bonding effect is so significant that even a compound such as $\mathbf{E}$ in Table 2 with only two substituents (an - $\mathrm{OH}$ on the radical carbon $(\mathrm{C} 2)$ and a $-\mathrm{CH}_{2} \mathrm{OH}$ at the hydroperoxide carbon $(\mathrm{C} 1)$ ) has a rate coefficient of $1.7 \times 10^{8} \mathrm{~s}^{-1}$ likely out-competing $\mathrm{O}_{2}$-addition. This is about a factor of 10 lower than the rate coefficient for $\mathbf{L}$, i.e. substituting the $-\mathrm{CH}_{3}$ group (on $\mathrm{C1}$ ) in $\mathbf{L}$ for an $-\mathrm{H}$ in $\mathbf{E}$ decreases the calculated rate coefficient by about a factor of 10 , as expected from Table 1 . 


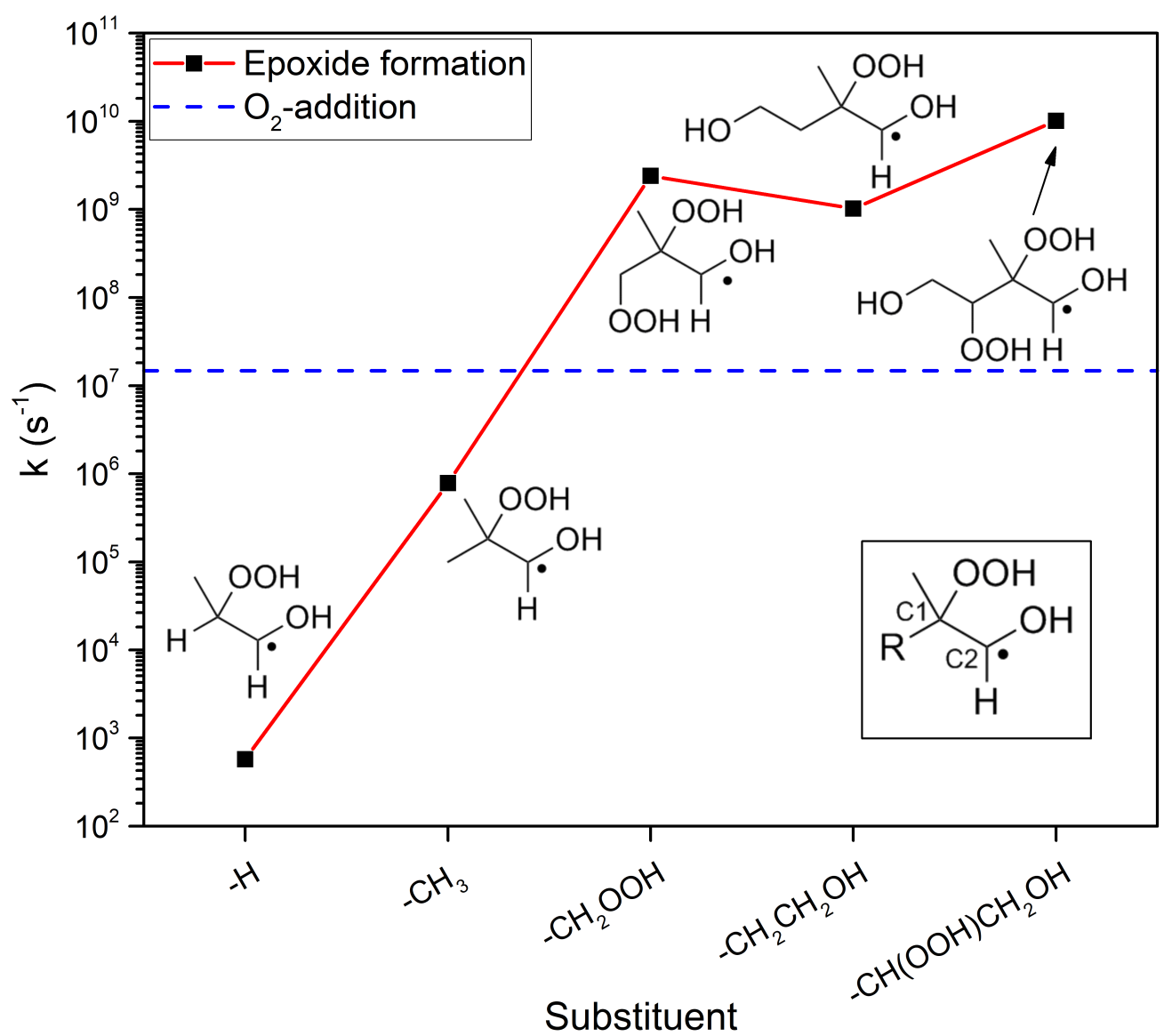

Figure 4: Reaction rate coefficient of epoxide formation as a function of the substituent at position $\mathrm{R}(\mathrm{C} 1)$ in the insert. The dashed blue line represents the pseudo first-order rate coefficient of $\mathrm{O}_{2}$-addition at $1.5 \times 10^{7} \mathrm{~s}^{-1} \cdot{ }^{9}$

It seems that a large part of the increase in the rate coefficient is related to H-bonding by the $\mathrm{OH}$-group bonded directly to the alkyl radical carbon atom. Adding a $-\mathrm{CH}_{2}$ group in between the alkyl radical $(\mathrm{C} 2)$ and the $-\mathrm{OH}$ group decreases the calculated reaction rate coefficient for system $\mathbf{E}$ in Table 2 from $1.7 \times 10^{8} \mathrm{~s}^{-1}$ to $2.8 \times 10^{4} \mathrm{~s}^{-1}$. The $\mathrm{CH}_{2}$-extension changes the hydrogen bonding pattern of the lowest-energy transition state conformer, so that the $\mathrm{OH}$-group now binds to the $-\mathrm{OOH}$ group that loses the $\mathrm{OH}$, rather than the other OH-group (Figure S6). 
Table 2: Structures of the reactants and reaction rate coefficients $\left(k \mathrm{in} \mathrm{s}^{-1}\right)$ for systems found with MC-TST rate coefficients of epoxide formation greater than $10^{7} \mathrm{~s}^{-1}$. The structures are sorted by increasing rate of reaction.

\begin{tabular}{|c|c|c|}
\hline Label & Reactant & $k$ \\
\hline A & & $1.4 \times 10^{7}$ \\
\hline B & & $1.8 \times 10^{7}$ \\
\hline $\mathrm{C}$ & & $3.2 \times 10^{7}$ \\
\hline D & & $1.3 \times 10^{8}$ \\
\hline $\mathbf{E}$ & & $1.7 \times 10^{8}$ \\
\hline $\mathbf{F}$ & & $2.1 \times 10^{8}$ \\
\hline $\mathrm{G}$ & & $2.2 \times 10^{8}$ \\
\hline $\mathbf{H}$ & & $6.4 \times 10^{8}$ \\
\hline I & & $6.5 \times 10^{8}$ \\
\hline $\mathbf{J}$ & & $1.0 \times 10^{9}$ \\
\hline $\mathbf{K}$ & & $2.4 \times 10^{9}$ \\
\hline $\mathbf{L}$ & & $3.5 \times 10^{9}$ \\
\hline M & & $1.0 \times 10^{10}$ \\
\hline
\end{tabular}

Replacing the hydroperoxy methyl group $\left(-\mathrm{CH}_{2} \mathrm{OOH}\right)$ on $\mathrm{C} 1$ in system $\mathbf{I}$ in Table 2 by a nitrooxy methyl group $\left(-\mathrm{CH}_{2} \mathrm{ONO}_{2}\right)$ decreases the reaction rate coefficient by more than three orders of magnitude making it uncompetitive with $\mathrm{O}_{2}$-addition. The difference between an $-\mathrm{CH}_{2} \mathrm{OH}$ and an $-\mathrm{CH}_{2} \mathrm{OOH}$ group is only about a factor of 4 (Systems $\mathbf{E}$ and $\mathbf{I}$ ). 


\section{Summary of Conditions for Fast Thermalized Epoxide For- mation}

Based on the systems studied here, it seems that epoxide formation from thermalized compounds is likely competitive with $\mathrm{O}_{2}$-addition under atmospheric conditions for systems with the following characteristics:

1. A $\beta$-hydroperoxy alkyl radical motif.

2. A hydroxy group at the alkyl radical carbon (C2).

3. An additional group at $\mathrm{C} 1$ (in addition to the hydroperoxy group) that the hydroxy group at $\mathrm{C} 2$ can form a hydrogen bond to. 
For systems fulfilling these requirements, our results suggest that epoxide formation needs to be considered. A likely key area of importance is in autoxidation which forms oxidized compounds with hydroperoxy groups and is thus likely to lead to systems with the characteristics outlined above. Epoxide formation may thus be an important autoxidation termination reaction. The one addition to the above conditions that we have observed is compound $\mathbf{G}$ in Table 2, which has a methoxy $\left(-\mathrm{OCH}_{3}\right)$ group at $\mathrm{C} 2$ rather than a hydrogen bonding $-\mathrm{OH}$ group and a rate coefficient for epoxide formation of $2.2 \times 10^{8} \mathrm{~s}^{-1}$. The epoxide formation may thus be slightly more general than the conditions outlined above would suggest. Further experimental validation of the proposed mechanism and its ability to outcompete $\mathrm{O}_{2}$-addition without the need for excess energy remains necessary to complement the recent results. ${ }^{12}$

\section{Related Mechanisms}

We investigated whether the thermalized epoxide formation mechanism is also a viable option for formation of larger cyclic ethers (see Figure 5 and Section S8). For the unsubstituted analogues we find that the reaction barrier is lower by about $2 \mathrm{kcal} / \mathrm{mol}$ for the formation of five- and six-membered cyclic ethers compared to the more strained three-membered epoxides. However, the entropic penalty from loss of conformational freedom causes the reaction rate coefficients to be comparable for formation of epoxides and 5- and 6-membered cyclic ethers. This entropic penalty for formation of larger cyclic ethers over epoxides has been found before. ${ }^{34,37,79}$ The formation of a four-membered cyclic ether has a significantly higher barrier and much lower rate of reaction. See Wijaya et al. ${ }^{36}$ for a comparison of literature Arrhenius parameters for formation of epoxides and larger cyclic ethers in the unsubstituted and alkyl-substituted systems. 

of 4-, 5- and 6-membered cyclic ethers. Different systems with one or more substituents at positions $R$ were studied (see Figure $\mathrm{S} 7$ ).

For the five- and six-membered ring forming systems, we observe the same trend as for the epoxide formation that substitution increases the rate of reaction. ${ }^{36}$ Still, the fastest system identified (formation of six-membered ring with two hydroxy groups) has a rate coefficient of $5.3 \times 10^{5} \mathrm{~s}^{-1}$, which is unlikely to be competitive with $\mathrm{O}_{2}$-addition. However, it is possible that systems do exist for which the formation of larger rings is competitive with $\mathrm{O}_{2}$-addition under atmospheric conditions. At the elevated temperatures encountered during combustion formation of larger cyclic ethers has been observed both theoretically and experimentally to be competitive even for unsubstituted systems. ${ }^{37,80,81}$

Formation of epoxides has been observed from $\beta$-nitrooxy $\left(-\mathrm{ONO}_{2}\right)$ alkyl radicals in IEPOXanalog reactions progressing via excess energy from $\mathrm{OH}$-addition. ${ }^{13}$ However, for a set of three representative systems (see Section S9), we find that the barrier for epoxide formation is higher for nitrooxy alkyl radicals than for the corresponding hydroperoxy alkyl radicals. This is in agreement with the experimental results showing a smaller IEPOX yield from the nitrooxy ISOPOOH analog. ${ }^{2,8,13}$ For the systems tested here, we therefore find that epoxide formation from $\beta$-nitrooxy alkyl radicals is too slow to matter under atmospheric conditions without excess energy. The difference seems to increase with the rate coefficient so that the faster reactions have larger differences between the rate of epoxide formation from $\beta$ - 
hydroperoxy and $\beta$-nitrooxy alkyl radicals.

A third group of compounds that may form epoxides are organic peroxides which are formed by reaction of two peroxy radicals and have been observed during oxidation of many important biogenic compounds. ${ }^{82,83}$ Using a set of three simple peroxides with an methyl group on one side of the peroxy group and a variable alkyl group at the other (see Table S11), we find that the rate coefficient of epoxide formation from the organic peroxides is slightly higher than for the corresponding hydroperoxides, with differences ranging from a factor of three to more than a factor of 100 . This may be explained by lower bond dissociation enthalpies for $\mathrm{RO}-\mathrm{OCH}_{3}$ bonds compared to $\mathrm{RO}-\mathrm{OH}$ bonds. ${ }^{36}$ This suggests that epoxide formation may also represent an important atmospheric oxidation pathway in the oxidation of organic peroxides with suitable substituents. In addition to an epoxide, this reaction forms an alkoxy radical (RO). Our calculated rate coefficients are in reasonable agreement with the corresponding experimental liquid-phase values (see Section S10).

The potentially competing unimolecular $\mathrm{HO}_{2}$-loss from the $\beta$ hydroperoxy alkyl radicals to form the unsaturated species was investigated for three selected systems (see Section S11). In all three, $\mathrm{HO}_{2}$-loss was found to be much slower than epoxide formation and, as found previously, highly uncompetitive with $\mathrm{O}_{2}$-addition. ${ }^{84}$

\section{Atmospheric Implications}

As a measure of the prevalence of thermalized epoxide formation in the atmosphere, we surveyed the oxidation mechanism of isoprene, as reviewed recently by Wennberg et al. ${ }^{7}$ and implemented in Bates and $\mathrm{Jacob}^{45}$. Addition of $\mathrm{OH}$ to ISOPOOH forms four different $\beta$-hydroperoxy alkyl radicals which all possess the outlined characteristics expected to lead to fast thermalized epoxide formation producing four distinct isoprene dihydroxy hydroper- 
The atmospheric importance of thermalized epoxide formation was assessed by a global simulation of isoprene oxidation using GEOS-Chem. ${ }^{744,45}$ The pathway to IDHPE from ISOPOOH vastly dominates the thermalized epoxide formation, while the other pathways, IHNPE formation from IPN and epoxide formation from IDHDP, are negligible on a global scale due to low yields of their precursors (see Table S15), but may be locally important. However, with an annual global production of $23 \mathrm{Tg}$, IDHPE is by far the most abundant individual C5-tetrafunctional compound from isoprene oxidation. On a global and annual average, IDHPE has an overall $3.6 \%$ molar yield (7.8 \% mass yield) from isoprene. In comparison, the important isoprene epoxide diols (IEPOX) have a $20 \%$ molar yield (35\% mass yield). ${ }^{2}$ This shows that though the outlined characteristics for fast epoxide formation might seem restrictive, they are met during atmospheric isoprene oxidation suggesting that this reaction may be an important termination reaction also in the oxidation of other VOCs.

Epoxides are known to be constituents of ambient SOA that can be modulated by anthropogenic perturbations to sulphate aerosol. ${ }^{21-24}$ In our GEOS-Chem modeling of isoprene oxidation, IDHPE contributes $26 \%\left(\sim 20 \mathrm{Tg} \mathrm{a}^{-1}\right)$ of the total SOA mass from isoprene. This is comparable to the SOA mass contribution from IEPOX, which is known to be important 
for formation of isoprene SOA. ${ }^{21,22,24,85}$ This value for IDHPE, represents an upper limit and is quite uncertain, as all the C5 tetrafunctional species in the GEOS-Chem model currently retain the high uptake coefficient implemented for analogous species by Fisher et al. ${ }^{86}$ As a lower limit, it can be assumed that IDHPE contributes to SOA formation and growth as efficiently as IEPOX. As the mass yield of IDHPE is about $20 \%$ that of IEPOX, IDHPE is expected to contribute at least $20 \%$ of the IEPOX contribution to annual SOA formation corresponding to more than $4 \mathrm{Tg} \mathrm{a}^{-1}$. This value likely represents a lower limit, as the additional hydroperoxy group in IDHPE compared to IEPOX means that it is likely more soluble and less volatile than IEPOX, and therefore probably more efficient at contributing to SOA directly and through subsequent particle phase chemistry. Even at the lower limit, this shows that thermalized epoxide formation is likely important for the atmospheric formation of SOA and highlights the need to better constrain the rates and mechanisms of SOA formation from the types of epoxides studied herein.

As noted in the introduction, thermalized epoxide formation studied herein may well be an important termination of peroxy radical autoxidation pathways. These pathways lead to highly oxygenated peroxy radicals which are considered to often self-terminate via an intramolecular abstraction of a hydrogen from a carbon atom containing a hydroperoxy or hydroxy group to produce a carbonyl and $\mathrm{OH}$ or $\mathrm{HO}_{2}$ (Scheme 2). Our calculations suggest that should the highly oxygenated peroxy radical abstract a hydrogen from a carbon containing an hydroxy group adjacent to a carbon containing an hydroperoxy group, then an epoxide will be produced along with an $\mathrm{OH}$ (Scheme 2, lower pathway). 

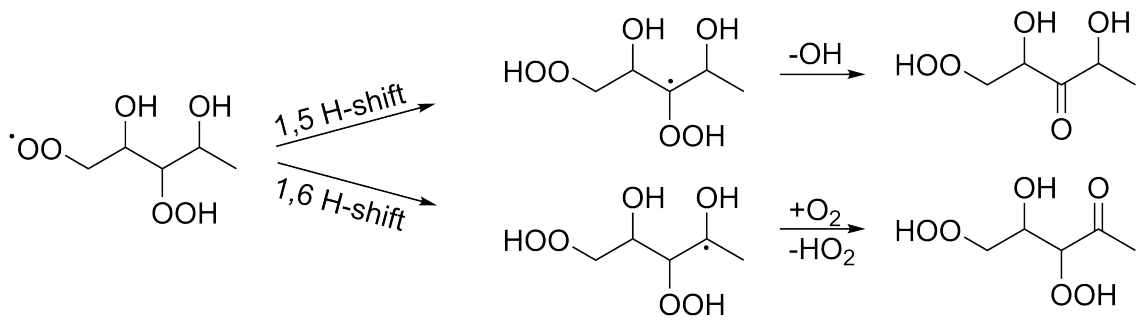

Scheme 2: Example of the termination of autoxidation following H-shifts leading to formation of either a ketone plus $\mathrm{OH}$ or $\mathrm{HO}_{2}$ or an epoxide plus $\mathrm{OH}$.

The proposed epoxide formation autoxidation termination reactions require the compounds to be highly oxidized. For the $\alpha$-hydroxy alkyl radicals that are the requirement for epoxide formation, the alternative reaction is addition of $\mathrm{O}_{2}$ followed by loss of $\mathrm{HO}_{2}$ to form a carbonyl compound. ${ }^{10}$ The epoxide formation is thus unlikely to terminate the autoxidation process faster than otherwise, but will lead to formation of epoxides and $\mathrm{OH}$ rather than carbonyl species and $\mathrm{HO}_{2}$.

The importance of thermalized epoxide formation is likely limited to low $\mathrm{NO}_{x}$-conditions which favor mechanisms that lead to $\mathrm{OH}$ and $\mathrm{OOH}$ hydrogen bonding moeities on and adjacent to alkyl radicals. However, due to the focus on limiting $\mathrm{NO}_{x}$ emissions, the average atmospheric $\mathrm{NO}_{x}$ concentrations are decreasing in many locations enhancing the importance of autoxidation and thus also this potential autoxidation termination reaction. ${ }^{72}$ Decreasing $\mathrm{NO}_{x}$ in cities could lead to increased epoxide formation via the mechanism studied here which may have important consequences due to the known mutagenic and carcinogenic toxicity of epoxides in humans. ${ }^{87,88}$ Also, the increased global average temperatures would enhance autoxidation and thus epoxide formation. 


\section{Supporting Information Available}

Rate coefficients and associated barrier heights and summed, weighted partition functions for all $\beta$-hydroperoxy alkyl radical epoxide formation reactions, all $\beta$-nitrooxy alkyl radical epoxide formation reactions, $\beta$-methylperoxy alkyl radical epoxide formation reactions $\mathrm{HO}_{2^{-}}$ loss and formation of larger cyclic ethers, assessment of tunneling, details of the RRKM modeling, details of the approach for obtaining the lowest-energy HF solution, details of the MRCI calculations and output from the GEOS-Chem modeling.

All $\omega$ B97X-D/aug-cc-pVTZ and F12 output files, which include the $\omega$ B97X-D/aug-cc-pVTZ optimized geometries, are available at: https://sid.erda.dk/sharelink/EAW9QlKocz

\section{Author Information}

\section{Corresponding Author}

* (H.G.K.): E-mail: hgk@chem.ku.dk

\section{ORCID}

Kristian H. Møller: 0000-0001-8070-8516

Theo Kurtén: 0000-0002-6416-4931

Kelvin H. Bates: 0000-0001-7544-9580

Joel A. Thornton: 0000-0002-5098-4867

Henrik G. Kjaergaard: 0000-0002-7275-8297

\section{Notes}

The authors declare no competing financial interest. 


\section{Acknowledgement}

We are grateful to Paul O. Wennberg for helpful discussions. We would like to thank Jakub Kubecka for his work on implementing the solution for obtaining the lowest Hartee-Fock solution during calculations. We acknowledge the financial support from the Alfred P. Sloan Foundation's program Chemistry of Indoor Environments, the Independent Research Fund Denmark and the University of Copenhagen. We thank CSC - IT Center for Science, Finland for computational resources. K. H. M. is grateful for the financial support of the Danish Ministry of Higher Education and Science's Elite Research travel grant. T.K. acknowledges the financial support from of the Academy of Finland. J.A.T. was supported by a grant from the U.S. National Science Foundation (NSF CHE 1807204).

\section{References}

(1) Orlando, J. J.; Tyndall, G. S. Laboratory Studies of Organic Peroxy Radical Chemistry: An Overview with Emphasis on Recent Issues of Atmospheric Significance. Chem. Soc. Rev. 2012, 41, 6294-6317.

(2) Paulot, F.; Crounse, J. D.; Kjaergaard, H. G.; Kürten, A.; St. Clair, J. M.; Seinfeld, J. H.; Wennberg, P. O. Unexpected Epoxide Formation in the Gas-Phase Photooxidation of Isoprene. Science 2009, 325, 730-733.

(3) Guenther, A.; Hewitt, C. N.; Erickson, D.; Fall, R.; Geron, C.; Graedel, T.; Harley, P.; Klinger, L.; Lerdau, M.; Mckay, W. A. et al. A Global Model of Natural Volatile Organic Compound Emissions. J. Geophys. Res. Atmos. 1995, 100, 8873-8892.

(4) Guenther, A.; Karl, T.; Harley, P.; Wiedinmyer, C.; Palmer, P. I.; Geron, C. Estimates of Global Terrestrial Isoprene Emissions using MEGAN (Model of Emissions of Gases and Aerosols from Nature). Atmos. Chem. Phys. 2006, 6, 3181-3210. 
(5) Kesselmeier, J.; Staudt, M. Biogenic Volatile Organic Compounds (VOC): An Overview on Emission, Physiology and Ecology. J. Atmos. Chem. 1999, 33, 23-88.

(6) Guenther, A. B.; Jiang, X.; Heald, C. L.; Sakulyanontvittaya, T.; Duhl, T.; Emmons, L. K.; Wang, X. The Model of Emissions of Gases and Aerosols from Nature Version 2.1 (MEGAN2.1): An Extended and Updated Framework for Modeling Biogenic Emissions. Geosci. Model Dev. 2012, 5, 1471-1492.

(7) Wennberg, P. O.; Bates, K. H.; Crounse, J. D.; Dodson, L. G.; McVay, R. C.; Mertens, L. A.; Nguyen, T. B.; Praske, E.; Schwantes, R. H.; Smarte, M. D. et al. Gas-Phase Reactions of Isoprene and Its Major Oxidation Products. Chem. Rev. 2018, 118, 3337-3390.

(8) St. Clair, J. M.; Rivera-Rios, J. C.; Crounse, J. D.; Knap, H. C.; Bates, K. H.; Teng, A. P.; Jørgensen, S.; Kjaergaard, H. G.; Keutsch, F. N.; Wennberg, P. O. Kinetics and Products of the Reaction of the First-Generation Isoprene Hydroxy Hydroperoxide (ISOPOOH) with OH. J. Phys. Chem. A 2016, 120, 1441-1451.

(9) Wu, D.; Bayes, K. D. Rate Constants for the Reactions of Isobutyl, Neopentyl, Cyclopentyl, and Cyclohexyl Radicals with Molecular Oxygen. Int. J. Chem. Kinet. 1986, $18,547-554$.

(10) Atkinson, R. Gas-Phase Tropospheric Chemistry of Volatile Organic Compounds: 1. Alkanes and Alkenes. J. Phys. Chem. Ref. Data 1997, 26, 215-290.

(11) Park, J.; Jongsma, C. G.; Zhang, R.; North, S. W. OH/OD Initiated Oxidation of Isoprene in the Presence of $\mathrm{O}_{2}$ and NO. J. Phys. Chem. A 2004, 108, 10688-10697.

(12) D’Ambro, E. L.; Møller, K. H.; Lopez-Hilfiker, F. D.; Schobesberger, S.; Liu, J.; Shilling, J. E.; Lee, B. H.; Kjaergaard, H. G.; Thornton, J. A. Isomerization of SecondGeneration Isoprene Peroxy Radicals: Epoxide Formation and Implications for Secondary Organic Aerosol Yields. Environ. Sci. Technol. 2017, 51, 4978-4987. 
(13) Jacobs, M. I.; Burke, W. J.; Elrod, M. J. Kinetics of the Reactions of Isoprene-Derived Hydroxynitrates: Gas Phase Epoxide Formation and Solution Phase Hydrolysis. Atmos. Chem. Phys. 2014, 14, 8933-8946.

(14) Møller, K. H.; Otkjær, R. V.; Hyttinen, N.; Kurtén, T.; Kjaergaard, H. G. Cost-Effective Implementation of Multiconformer Transition State Theory for Peroxy Radical Hydrogen Shift Reactions. J. Phys. Chem. A 2016, 120, 10072-10087.

(15) Møller, K. H.; Bates, K. H.; Kjaergaard, H. G. The Importance of Peroxy Radical Hydrogen-Shift Reactions in Atmospheric Isoprene Oxidation. J. Phys. Chem. A 2019, 123, 920-932.

(16) Krechmer, J. E.; Coggon, M. M.; Massoli, P.; Nguyen, T. B.; Crounse, J. D.; Hu, W.; Day, D. A.; Tyndall, G. S.; Henze, D. K.; Rivera-Rios, J. C. et al. Formation of Low Volatility Organic Compounds and Secondary Organic Aerosol from Isoprene Hydroxyhydroperoxide Low-NO Oxidation. Environ. Sci. Technol. 2015, 49, 10330-10339.

(17) Twomey, S. Aerosols, Clouds and Radiation. Atmos. Environ. Part A. Gen. Top. 1991, 25, 2435 - 2442, Symposium on Global Climatic Effects of Aerosols.

(18) Takemura, T.; Nakajima, T.; Dubovik, O.; Holben, B. N.; Kinne, S. Single-Scattering Albedo and Radiative Forcing of Various Aerosol Species with a Global ThreeDimensional Model. J. Climate 2002, 15, 333-352.

(19) IPCC, Climate Change 2013: The Physical Science Basis. Contribution of Working Group I to the Fifth Assessment Report of the Intergovernmental Panel on Climate Change; Cambridge University Press: Cambridge, United Kingdom and New York, NY, USA, 2013; p 1535.

(20) Brauer, M.; Freedman, G.; Frostad, J.; van Donkelaar, A.; Martin, R. V.; Dentener, F.; van Dingenen, R.; Estep, K.; Amini, H.; Apte, J. S. et al. Ambient Air Pollution 
Exposure Estimation for the Global Burden of Disease 2013. Environ. Sci. Technol. 2016, 50, 79-88.

(21) Lin, Y.-H.; Zhang, Z.; Docherty, K. S.; Zhang, H.; Budisulistiorini, S. H.; Rubitschun, C. L.; Shaw, S. L.; Knipping, E. M.; Edgerton, E. S.; Kleindienst, T. E. et al. Isoprene Epoxydiols as Precursors to Secondary Organic Aerosol Formation: AcidCatalyzed Reactive Uptake Studies with Authentic Compounds. Environ. Sci. Technol. 2012, 46, 250-258.

(22) Budisulistiorini, S. H.; Canagaratna, M. R.; Croteau, P. L.; Marth, W. J.; Baumann, K.; Edgerton, E. S.; Shaw, S. L.; Knipping, E. M.; Worsnop, D. R.; Jayne, J. T. et al. RealTime Continuous Characterization of Secondary Organic Aerosol Derived from Isoprene Epoxydiols in Downtown Atlanta, Georgia, Using the Aerodyne Aerosol Chemical Speciation Monitor. Environ. Sci. Technol. 2013, 47, 5686-5694.

(23) Nguyen, T. B.; Coggon, M. M.; Bates, K. H.; Zhang, X.; Schwantes, R. H.; Schilling, K. A.; Loza, C. L.; Flagan, R. C.; Wennberg, P. O.; Seinfeld, J. H. Organic Aerosol Formation from the Reactive Uptake of Isoprene Epoxydiols (IEPOX) onto non-acidified inorganic seeds. Atmos. Chem. Phys. 2014, 14, 3497-3510.

(24) Budisulistiorini, S. H.; Li, X.; Bairai, S. T.; Renfro, J.; Liu, Y.; Liu, Y. J.; McKinney, K. A.; Martin, S. T.; McNeill, V. F.; Pye, H. O. T. et al. Examining the Effects of Anthropogenic Emissions on Isoprene-Derived Secondary Organic Aerosol Formation during the 2013 Southern Oxidant and Aerosol Study (SOAS) at the Look Rock, Tennessee Ground Site. Atmos. Chem. Phys. 2015, 15, 8871-8888.

(25) Surratt, J. D.; Chan, A. W. H.; Eddingsaas, N. C.; Chan, M.; Loza, C. L.; Kwan, A. J.; Hersey, S. P.; Flagan, R. C.; Wennberg, P. O.; Seinfeld, J. H. Reactive Intermediates Revealed in Secondary Organic Aerosol Formation from Isoprene. Proc. Natl. Acad. Sci. 2010, 10\%, 6640-6645. 
(26) Nguyen, T. B.; Bates, K. H.; Crounse, J. D.; Schwantes, R. H.; Zhang, X.; Kjaergaard, H. G.; Surratt, J. D.; Lin, P.; Laskin, A.; Seinfeld, J. H. et al. Mechanism of the Hydroxyl Radical Oxidation of Methacryloyl Peroxynitrate (MPAN) and its Pathway toward Secondary Organic Aerosol Formation in the Atmosphere. Phys. Chem. Chem. Phys. 2015, 17, 17914-17926.

(27) Lin, Y.-H.; Zhang, H.; Pye, H. O. T.; Zhang, Z.; Marth, W. J.; Park, S.; Arashiro, M.; Cui, T.; Budisulistiorini, S. H.; Sexton, K. G. et al. Epoxide as a Precursor to Secondary Organic Aerosol Formation from Isoprene Photooxidation in the Presence of Nitrogen Oxides. Proc. Natl. Acad. Sci. 2013, 110, 6718-6723.

(28) Eddingsaas, N. C.; VanderVelde, D. G.; Wennberg, P. O. Kinetics and Products of the Acid-Catalyzed Ring-Opening of Atmospherically Relevant Butyl Epoxy Alcohols. J. Phys. Chem. A 2010, 114, 8106-8113.

(29) Azizi, N.; Saidi, M. R. Highly Chemoselective Addition of Amines to Epoxides in Water. Org. Lett. 2005, 7, 3649-3651.

(30) Stropoli, S. J.; Elrod, M. J. Assessing the Potential for the Reactions of Epoxides with Amines on Secondary Organic Aerosol Particles. J. Phys. Chem. A 2015, 119, $10181-10189$.

(31) Bloodworth, A. J.; Davies, A. G.; Griffin, I. M.; Muggleton, B.; Roberts, B. P. Rate Constants for the Formation of Oxiranes from $\beta$-Peroxyalkyl Radicals. The gem-Dialkyl Effect in Homolytic Ring Closure. J. Am. Chem. Soc. 1974, 96, 7599-7601.

(32) Budnik, R. A.; Kochi, J. K. Epoxidation of Olefins with Molecular Oxygen in the Presence of Cobalt Complexes. J. Org. Chem. 1976, 41, 1384-1389.

(33) Baldwin, R. R.; Stout, D. R.; Walker, R. W. Arrhenius Parameters for the Addition of $\mathrm{HO}_{2}$ Radicals to Ethene between 400 and $500{ }^{\circ}$ C. J. Chem. Soc., Faraday Trans. 1991, 87, 2147-2150. 
(34) Chan, W.-T.; O. Pritchard, H.; P. Hamilton, I. Dissociative Ring-Closure in Aliphatic Hydroperoxyl Radicals. Phys. Chem. Chem. Phys. 1999, 1, 3715-3719.

(35) Sheng, C. Y.; Bozzelli, J. W.; Dean, A. M.; Chang, A. Y. Detailed Kinetics and Thermochemistry of $\mathrm{C}_{2} \mathrm{H}_{5}+\mathrm{O}_{2}$ : Reaction Kinetics of the Chemically-Activated and Stabilized $\mathrm{CH}_{3} \mathrm{CH}_{2} \mathrm{OO} \bullet$ Adduct. J. Phys. Chem. A 2002, 106, 7276-7293.

(36) Wijaya, C. D.; Sumathi, R.; Green, W. H. Thermodynamic Properties and Kinetic Parameters for Cyclic Ether Formation from Hydroperoxyalkyl Radicals. J. Phys. Chem. A 2003, 107, 4908-4920.

(37) Miyoshi, A. Systematic Computational Study on the Unimolecular Reactions of Alkylperoxy $\left(\mathrm{RO}_{2}\right)$, Hydroperoxyalkyl (QOOH), and Hydroperoxyalkylperoxy ( $\left.\mathrm{O}_{2} \mathrm{QOOH}\right)$ Radicals. J. Phys. Chem. A 2011, 115, 3301-3325.

(38) Villano, S. M.; Huynh, L. K.; Carstensen, H.-H.; Dean, A. M. High-Pressure Rate Rules for Alkyl $+\mathrm{O}_{2}$ Reactions. 2. The Isomerization, Cyclic Ether Formation, and $\beta$-Scission Reactions of Hydroperoxy Alkyl Radicals. J. Phys. Chem. A 2012, 116, 5068-5089.

(39) Cord, M.; Sirjean, B.; Fournet, R.; Tomlin, A.; Ruiz-Lopez, M.; Battin-Leclerc, F. Improvement of the Modeling of the Low-Temperature Oxidation of $n$-Butane: Study of the Primary Reactions. J. Phys. Chem. A 2012, 116, 6142-6158.

(40) Bugler, J.; Power, J.; Curran, H. J. A Theoretical Study of Cyclic Ether Formation Reactions. Proc. Combust. Inst. 2017, 36, $161-167$.

(41) Oakley, L. H.; Casadio, F.; Shull, K. R.; Broadbelt, L. J. Theoretical Study of Epoxidation Reactions Relevant to Hydrocarbon Oxidation. Ind. Eng. Chem. Res. 2017, 56, $7454-7461$.

(42) Baldwin, R. R.; Drewery, G. R.; Walker, R. W. Decomposition of 2,3-Dimethylbutane 
in the Presence of Oxygen. Part 2.-Elementary Reactions Involved in the Formation of Products. J. Chem. Soc., Faraday Trans. 1 1984, 80, 3195-3207.

(43) Dagaut, P.; Reuillon, M.; Cathonnet, M.; Presvots, D. Gas Chromatography and Mass Spectrometry Identification of Cyclic Ethers Formed from Reference Fuels Combustion. Chromatographia 1995, 40, 147-154.

(44) Bey, I.; Jacob, D. J.; Yantosca, R. M.; Logan, J. A.; Field, B.; Fiore, A. M.; Li, Q.; Liu, H.; Mickley, L. J.; Schultz, M. Global Modeling of Tropospheric Chemistry with Assimilated Meteorology: Model Description and Evaluation. J. Geophys. Res. 2001, 106, 23073-23096.

(45) Bates, K. H.; Jacob, D. J. A New Model Mechanism for Atmospheric Oxidation of Isoprene: Global Effects on Oxidants, Nitrogen Oxides, Organic Products, and Secondary Organic Aerosol. Atmos. Chem. Phys. 2019, 19, 9613-9640.

(46) Becke, A. D. Density-Functional Thermochemistry. III. The Role of Exact Exchange. J. Chem. Phys. 1993, 98, 5648-5652.

(47) Lee, C.; Yang, W.; Parr, R. G. Development of the Colle-Salvetti Correlation-Energy Formula into a Functional of the Electron Density. Phys. Rev. B 1988, 37, 785-789.

(48) Hehre, W. J.; Ditchfield, R.; Pople, J. A. Self-Consistent Molecular Orbital Methods. XII. Further Extensions of Gaussian-Type Basis Sets for Use in Molecular Orbital Studies of Organic Molecules. J. Chem. Phys. 1972, 56, 2257-2261.

(49) Clark, T.; Chandrasekhar, J.; Spitznagel, G. W.; Schleyer, P. V. R. Efficient Diffuse Function-augmented Basis Sets for Anion Calculations. III. The 3-21+G Basis Set for First-row Elements, Li-F. J. Comput. Chem. 1983, 4, 294-301.

(50) Frisch, M. J.; Pople, J. A.; Binkley, J. S. Self-consistent Molecular Orbital Methods 25. Supplementary Functions for Gaussian Basis Sets. J. Chem. Phys. 1984, 80, 3265-3269. 
(51) Frisch, M. J.; Trucks, G. W.; Schlegel, H. B.; Scuseria, G. E.; Robb, M. A.; Cheeseman, J. R.; Scalmani, G.; Barone, V.; Mennucci, B.; Petersson, G. A. et al. Gaussian 09 Revision D.01. Gaussian Inc. Wallingford CT 2009.

(52) Spartan '14. Wavefunction Inc., Irvine, CA.

(53) Halgren, T. A. Merck Molecular Force Field. I. Basis, Form, Scope, Parameterization, and Performance of MMFF94. J. Comput. Chem. 1996, 17, 490-519.

(54) Otkjær, R. V.; Møller, K. H. Removal of Duplicate Conformers. https ://github.com/ TheKjaergaardGroup/Removal-of-Duplicate-Conformers.

(55) Chai, J.-D.; Head-Gordon, M. Long-range Corrected Hybrid Density Functionals with Damped Atom-atom Dispersion Corrections. Phys. Chem. Chem. Phys. 2008, 10, 66156620 .

(56) Dunning, T. H. Gaussian Basis Sets for Use in Correlated Molecular Calculations. I. The Atoms Boron Through Neon and Hydrogen. J. Chem. Phys. 1989, 90, 1007-1023.

(57) Kendall, R. A.; Dunning, T. H.; Harrison, R. J. Electron Affinities of the First-row Atoms Revisited. Systematic Basis Sets and Wave Functions. J. Chem. Phys. 1992, $96,6796-6806$.

(58) Werner, H.-J.; Knowles, P. J.; Knizia, G.; Manby, F. R.; Schütz, M.; Celani, P.; Györffy, W.; Kats, D.; Korona, T.; Lindh, R. et al. MOLPRO, version 2012.1, a package of ab initio programs. 2012; see http://www.molpro.net.

(59) Watts, J. D.; Gauss, J.; Bartlett, R. J. Coupled-cluster Methods with Noniterative Triple Excitations for Restricted Open-shell Hartree-Fock and Other General Single Determinant Reference Functions. Energies and Analytical Gradients. J. Chem. Phys. 1993, 98, 8718-8733. 
(60) Adler, T. B.; Knizia, G.; Werner, H.-J. A Simple and Efficient CCSD(T)-F12 Approximation. J. Chem. Phys. 2007, 127, 221106.

(61) Knizia, G.; Adler, T. B.; Werner, H.-J. Simplified CCSD(T)-F12 Methods: Theory and Benchmarks. J. Chem. Phys. 2009, 130, 054104.

(62) Werner, H.-J.; Knizia, G.; Manby, F. R. Explicitly Correlated Coupled Cluster Methods with Pair-specific Geminals. Mol. Phys. 2011, 109, 407-417.

(63) Peterson, K. A.; Adler, T. B.; Werner, H.-J. Systematically Convergent Basis Sets for Explicitly Correlated Wavefunctions: The Atoms H, He, B-Ne, and Al-Ar. J. Chem. Phys. 2008, 128, 084102.

(64) Eyring, H. The Activated Complex in Chemical Reactions. J. Chem. Phys. 1935, 3, $107-115$.

(65) Evans, M. G.; Polanyi, M. Some Applications of the Transition State Method to the Calculation of Reaction Velocities, Especially in Solution. Trans. Faraday Soc. 1935, $31,875-894$.

(66) Vereecken, L.; Peeters, J. The 1,5-H-shift in 1-Butoxy: A Case Study in the Rigorous Implementation of Transition State Theory for a Multirotamer System. J. Chem. Phys. 2003, 119, 5159-5170.

(67) Eckart, C. The Penetration of a Potential Barrier by Electrons. Phys. Rev. 1930, 35, $1303-1309$.

(68) Barker, J. R. Multiple-Well, Multiple-Path Unimolecular Reaction Systems. I. MultiWell Computer Program Suite. Int. J. Chem. Kinet. 2001, 33, 232-245.

(69) Barker, J. R. Energy Transfer in Master Equation Simulations: A New Approach. Int. J. Chem. Kinet. 2009, 41, 748-763. 
(70) Barker, J. R.; Nguyen, T. L.; Stanton, J. F.; Aieta, C.; Ceotto, M.; Gabas, F.; Kumar, T. J. D.; Li, C. G. L.; Lohr, L. L.; Maranzana, A. et al. MultiWell-2017 Software Suite. 2017; J. R. Barker, University of Michigan, Ann Arbor, Michigan, USA, http://claspresearch.engin.umich.edu/multiwell/.

(71) Vaucher, A. C.; Reiher, M. Steering Orbital Optimization out of Local Minima and Saddle Points Toward Lower Energy. J. Chem. Theory Comput. 2017, 13, 1219-1228.

(72) Praske, E.; Otkjær, R. V.; Crounse, J. D.; Hethcox, J. C.; Stoltz, B. M.; Kjaergaard, H. G.; Wennberg, P. O. Atmospheric Autoxidation is Increasingly Important in Urban and Suburban North America. Proc. Natl. Acad. Sci. U.S.A. 2018, 115, 6469.

(73) Praske, E.; Otkjær, R. V.; Crounse, J. D.; Hethcox, J. C.; Stoltz, B. M.; Kjaergaard, H. G.; Wennberg, P. O. Intramolecular Hydrogen Shift Chemistry of Hydroperoxy-Substituted Peroxy Radicals. The J. Phys. Chem. A 2019, 123, 590-600.

(74) Xu, L.; Møller, K. H.; Crounse, J. D.; Otkjær, R. V.; Kjaergaard, H. G.; Wennberg, P. O. Unimolecular Reactions of Peroxy Radicals Formed in the Oxidation of $\alpha$-Pinene and $\beta$-Pinene by Hydroxyl Radicals. J. Phys. Chem. A 2019, 123, 1661-1674.

(75) Møller, K. H.; Praske, E.; Xu, L.; Crounse, J. D.; Wennberg, P. O.; Kjaergaard, H. G. Stereoselectivity in Atmospheric Autoxidation. Just Accepted J. Phys. Chem. A 2019,

(76) Keller, C. A.; Long, M. S.; Yantosca, R. M.; Da Silva, A. M.; Pawson, S.; Jacob, D. J. HEMCO v1.0: A Versatile, ESMF-Compliant Component for Calculating Emissions in Atmospheric Models. Geosci. Model Dev. 2014, 7, 1409-1417.

(77) Vereecken, L.; Nguyen, T.; Hermans, I.; Peeters, J. Computational Study of the Stability of $\alpha$-Hydroperoxyl- or $\alpha$-Alkylperoxyl Substituted Alkyl Radicals. Chem. Phys. Lett. 2004, 393, $432-436$. 
(78) Vereecken, L. Computational study of the stability of $\alpha$-nitroxy-substituted alkyl radicals. Chemical Physics Letters 2008, 466, 127 - 130.

(79) Heine, H. W.; Siegfried, W. On Cyclic Intermediates in Substitution Reactions. V. The Alkaline Hydrolysis of Tetramethylene Chlorohydrin. J. Am. Chem. Soc. 1954, 76, 489-490.

(80) Knox, J. H.; Kinnear, C. The Mechanism of Combustion of Pentane in the Gas Phase between $250^{\circ}$ and $400^{\circ}$ C. Symp. Int. Combust. 1971, 13, $217-227$.

(81) Baldwin, R. R.; Hisham, M. W. M.; Walker, R. W. Arrhenius Parameters of Elementary Reactions Involved in the Oxidation of Neopentane. J. Chem. Soc., Faraday Trans. 1 1982, 78, 1615-1627.

(82) Ehn, M.; Thornton, J. A.; Kleist, E.; Sipilä, M.; Junninen, H.; Pullinen, I.; Springer, M.; Rubach, F.; Tillmann, R.; Lee, B. et al. A Large Source of Low-Volatility Secondary Organic Aerosol. Nature 2014, 506, 476-479.

(83) Berndt, T.; Scholz, W.; Mentler, B.; Fischer, L.; Herrmann, H.; Kulmala, M.; Hansel, A. Accretion Product Formation from Self- and Cross-Reactions of $\mathrm{RO}_{2}$ Radicals in the Atmosphere. Angew. Chem. Int. Ed. 2018, 57, 3820-3824.

(84) Hyttinen, N.; Knap, H. C.; Rissanen, M. P.; Jørgensen, S.; Kjaergaard, H. G.; Kurtén, T. Unimolecular $\mathrm{HO}_{2}$ Loss from Peroxy Radicals Formed in Autoxidation Is Unlikely under Atmospheric Conditions. J. Phys. Chem. A 2016, 120, 3588-3595.

(85) Worton, D. R.; Surratt, J. D.; LaFranchi, B. W.; Chan, A. W. H.; Zhao, Y.; Weber, R. J.; Park, J.-H.; Gilman, J. B.; de Gouw, J.; Park, C. et al. Observational Insights into Aerosol Formation from Isoprene. Environ. Sci. Technol. 2013, 47, 11403-11413.

(86) Fisher, J. A.; Jacob, D. J.; Travis, K. R.; Kim, P. S.; Marais, E. A.; Chan Miller, C.; Yu, K.; Zhu, L.; Yantosca, R. M.; Sulprizio, M. P. et al. Organic Nitrate Chemistry 
and its Implications for Nitrogen Budgets in an Isoprene- and Monoterpene-Rich Atmosphere: Constraints from Aircraft (SEAC $\left.{ }^{4} \mathrm{RS}\right)$ and Ground-Based (SOAS) Observations in the Southeast US. Atmos. Chem. Phys. 2016, 16, 5969-5991.

(87) Ehrenberg, L.; Hussain, S. Genetic Toxicity of some Important Epoxides. Mutat. Res./Rev. Genet. Tox. 1981, 86, 1- 113.

(88) Melnick, R. L. Carcinogenicity and Mechanistic Insights on the Behavior of Epoxides and Epoxide-Forming Chemicals. Ann. N. Y. Acad. Sci. 2002, 982, 177-189. 


\section{Graphical TOC Entry}

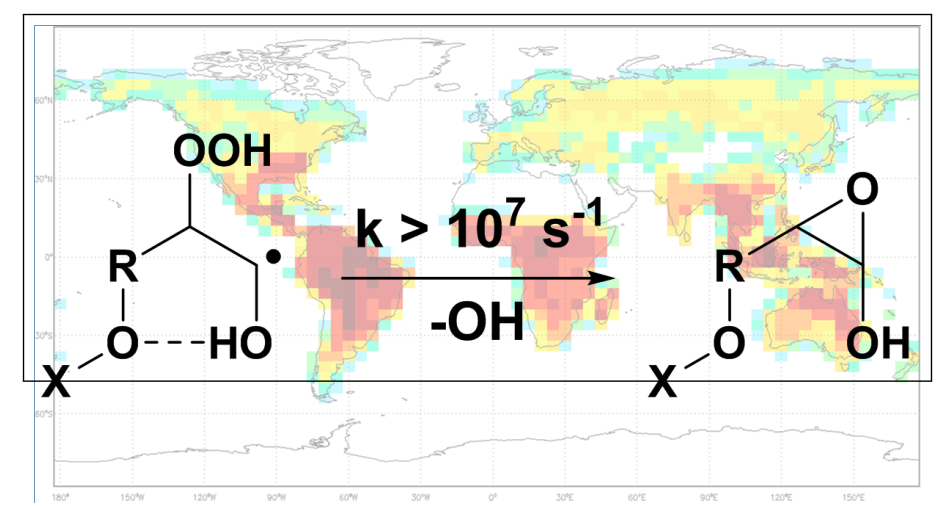

